\title{
Aproximações à medicina monástica em Portugal na Idade Média
}

\author{
Approaches to monastic medicine in Middle Ages' Portugal
}

Dulce O. Amarante dos SANTOS*

Resumo: Este texto investiga os indícios da existência de uma medicina monástica no reino de Portugal na Idade Média, antes e depois da fundação da Universidade em 1290, realizada por D. Dinis. O corpus de fontes analisado inclui regras beneditinas e agostinianas, costumeiros ou liber ordinis, catálogo das livrarias de mão do mosteiro de Santa Cruz de Coimbra, legislação conciliar. Assinala dois momentos basilares nessa história, sendo o primeiro a criação da regra beneditina no IV século, que resultou na criação de dois espaços próprios para o exercício da medicina monástica associados à prática da virtude da caridade: a enfermaria e o hospital. O segundo momento, no século XIII, constitui-se na institucionalização da escolástica médica e, ao mesmo tempo, nas tentativas de coibir a prática médica pelos religiosos nos sínodos regionais e no IV Concílio de Latrão (1215).

Palavras-chaves: medicina monástica, Portugal, Idade Média.

\begin{abstract}
This paper seeks to analyze the medieval Portuguese monastic medicine in the Middle Ages before and after the Universty's foundation at 1290 by the king D. Dinis. The sources corpus include beneditine and augustiani rules, liber ordinis or customaries, books catalogue from Santa Cruz of Coimbra and conciliary legislation. There were two basic moments of monastic medicine: the first had occurred in the $6^{\text {th }}$ century with the beneditine rule which had favoured the development of two spaces for the sicks monks and poors care, e. g., infirmary and hospital. The second moment, in the $13^{\text {th }}$ century focused the institucional medical scholasticism and at the same time the Church conciliar legis lation attempts to forbide for the monks the practica medica.
\end{abstract}

Keywords: monastic medicine, Portugal, Middle Ages

Que se considere a medicina como uma segunda filosofia.

Uma e outra ciência reclamam para si o homem inteiro;

pois se por meio de uma se cura a alma, por meio da outra se cura o corpo.

Isidoro de Sevilha, Etimologias

$\mathrm{Na}$ longa duração medieval, é importante ressaltar dois momentos basilares para a compreensão da história da medicina monástica europeia. O primeiro situa-se na primeira metade

\footnotetext{
* Professora Doutora- Programa de Pós-Graduação em História, Faculdade de História - UFG - Universidade Federal de Goiás, Campus II Samambaia, Caixa Postal 131, CEP 74001-970, Goiânia, Goiás. A pesquisa que resultou neste artigo contou com o financiamento do CNPq. Email: dulce@ historia.ufg.br
} 
do VI século, quando se deu, no reino ostrogodo da península itálica, o surgimento de regras monásticas compostas por homens religiosos imbuídos da utopia da fuga mundi. $\mathrm{O}$ segundo momento de inflexão da medicina monástica localiza-se nos inícios do século XIII, quando se instalaram os cursos de medicina nos Studia Generalia e se percebe a preocupação por parte da Igreja católica, nos sínodos regionais e nos concílios, por coibir o estudo e o exercício da medicina, remunerada ou não, pelos monges para além dos muros de suas comunidades.

No primeiro movimento, destacaram-se Cassiodoro (485-580), com a fundação do mosteiro Vivarium, ${ }^{l}$ e São Bento de Núrsia (c. 480 -560), primeiro em Subiaco - cenóbio dedicado aos santos protetores da arte médica, Cosme e Damião -, e depois no mosteiro de Monte Cassino. Esses homens iniciaram no Ocidente o processo de uniformização e disciplinamento da vida religiosa cenobítica, com a implantação contínua de comunidades masculinas em zonas rurais, espelhando-se nas experiências anteriores do cristianismo oriental, como a de São Pacomio (292-348), ainda na parte oriental do Império Romano. Podem-se elencar quatro normativas comuns dessa vida monástica masculina: a separação do mundo, a abstinência sexual, a organização de atividades religiosas quotidianas e as práticas ascéticas. Nesse momento, não havia o propósito de redes com obrigações mútuas, portanto muitos mosteiros seguiam a regra beneditina, mas eram autônomos em sua administração e tinham o abade eleito pela comunidade. Essa nova forma de religiosidade propagou-se pela Europa, originou a modalidade do clero regular da Igreja católica, com períodos de crises e reformas, e multiplicou-se no espaço e no tempo até a contemporaneidade.

Quais as relações estabelecidas entre regra e medicina monástica? Aqui nos interessam mais de perto as diretrizes práticas da regra de São Bento, de caráter mais geral, que tornaram possíveis tanto sua adoção e adaptação em regiões diversas quanto sua disseminação numa extensa rede de comunidades.

Antes de tudo e acima de tudo deve tratar-se dos enfermos de modo que se lhes sirva como verdadeiramente ao Cristo, pois Ele disse: "Fui enfermo e visitaste-me" e "Aquilo que fizestes a um destes pequeninos a mim fizestes". Mas que os próprios enfermos considerem que são servidos em honra a Deus e não entristeçam com sua superfluidade aos irmãos que lhes servem. No entanto, devem os doentes ser levados pacientemente, porque no meio deles se adquire recompensa mais copiosa. Portanto, tenha o abade o máximo cuidado para que não sofram nenhuma negligencia. Haja uma cela destinada especialmente a estes irmãos enfermos, e um servo temente a Deus, diligente e solícito (RSB, cap. 36).

Nesse sentido, esse capítulo 36 pode ser considerado emblemático ao enfatizar (antes de tudo e acima de tudo) o cuidado com os enfermos, pois esse foco resultou na criação de dois espaços 
próprios para o exercício da medicina monástica associados à prática da virtude da caridade. Tratase da domus infirmorum, presente no interior das abadias para o atendimento aos irmãos doentes, e dos hospitia ou albergarias, para a hospitalidade dos peregrinos (adventantes), tratamento dos enfermos, acolhimento de pobres (pauperes), indigentes e patronos idosos. O mesmo capítulo da regra aponta igualmente a responsabilidade do abade pelo tratamento dos enfermos e pela designação dos recursos humanos, oficiais responsáveis e materiais. Além disso, prescrevem-se hábitos de higiene, a alimentação necessária para manutenção da saúde bem como as diversas práticas terapêuticas disponíveis na medicina da época. Percebe-se, assim, um conhecimento partilhado da Dietética ou Higiene, um dos três ramos da arte médica prática e terapêutica da Antiguidade greco-romana e helenística, a qual sempre colocou o homem no centro de suas preocupações. O termo dieta (diaeta) era usado para designar o modo de vida ou o conjunto de hábitos corporais e mentais de um indivíduo, aí incluída a alimentação. O objetivo principal da Dietética era a preservação da saúde corporal, ou seja, ela constituía regras e conselhos para uma maneira de viver saudável que ajudasse a evitar o aparecimento das enfermidades (JACQUART, 1995, p.178).

No decorrer do século XI, essas diretrizes relativas à saúde dos monges e ao cuidado com os enfermos chegaram ao reino portucalense por dois caminhos da reforma beneditina na região da França. O primeiro foi a adoção da regra dos beneditinos cluniacenses pelos antigos mosteiros hispânicos masculinos da diocese de Braga, no noroeste peninsular, como é o caso do mosteiro de Santa Maria do Pombeiro, em exame, e mais tarde a segunda via foi a dos cistercienses, ambos patrocinados pelas linhagens regionais e pelo poder régio. Outra vertente da vida monástica foi a canônica, optante da regra de Santo Agostinho, cujo exemplo mais notável foi o mosteiro de Santa Cruz de Coimbra (1132). Sua fundação imbricou-se com a própria formação do reino portucalense, pois recebeu apoio de Afonso Henriques quando este transferiu sua corte de Guimarães para Coimbra, com a dotação dos banhos régios da cidade. Tornou-se o local onde o rei buscava seus auxiliares e diplomatas e guardava seu tesouro e os documentos de sua chancelaria. Os dois documentos normativos, a regra agostiniana e o costumeiro seguiram os modelos do mosteiro de São Rufo de Avinhão (1080), na França, para onde se deslocaram monges, entre 1135 e 1139, com o objetivo de copiar os livros originais. Embora a primeira parte do costumeiro tenha como modelo o de São Rufo de Avinhão, a segunda parte mostra o esforço de adaptação à realidade do reino português, consultando-se outros padrões, inclusive os Costumes de Cister, do mosteiro de Alcobaça. A questão da assistência aos pobres e doentes concretizou-se entre 1148 e 1150, quando 
o seu primeiro prior, S. Teotónio, fundou o Hospital de São Nicolau. Seu sucessor, o segundo prior, D. João Teotónio, promoveu sua reorganização, ampliação e instalação em edifício próprio, e seu sustento provinha dos dízimos de todos os bens e rendimentos comunitários (MARTINS, 2003, pp. 261-267; MATTOSO, 1985, pp. 104, 119; SOUSA, 2005, p. 68-69).

Ademais, não se deve esquecer o papel desempenhado pelos scriptoria dos mosteiros beneditinos e dos crúzios na criação de bibliotecas e na conservação, compilação, cópia, tradução e salvaguarda de parte do patrimônio da cultura médica antiga e medieval. Nesse sentido, o Catálogo dos códices da livraria de mão do Mosteiro de Santa Cruz na Biblioteca Pública Municipal do Porto (1997) evidencia a presença - em meio aos textos patrísticos, breviários, livros de lembranças, saltérios, pontificais, vidas, evangeliários, sermonários, cânticos, hinos, litanias, costumeiros, missais, epistolários - de oito fragmentos, manuscritos e impressos de textos médicos, sendo dois deles o Commentaria in Aphorismos Hippocratis do pseudo Oribásio e o Alphabetum ad Paternum, atribuído ao Pseudo Galeno o catálogo de plantas e elementos ativos com virtudes medicinais. Além desse, há também alguns fragmentos: De Fumachi, De tríplice tumor, De multitudine palpitationis, De Lapidoatate (CCSCC, 13, 39, p.103). Em 1175, há registro, no Livro das Calendas da Sé de Coimbra, da doação de um conjunto de obras das diversas áreas do conhecimento pela morte do Mestre Martim, em Paris. A biblioteca do mestre doada incluía obras de teologia, história, medicina, filosofia, liturgia, aritmética, exegese bíblica e astronomia (MEIRINHOS, 1996, p. 161). No contexto histórico medieval é quase impossível diferenciar claramente as diversas esferas da atividade intelectual devido ao caráter integrado e relacional do conteúdo da cultura. Consequentemente, a presença de obras médicas demonstra o interesse e o conhecimento partilhado das teorias e das práticas médicas, disponíveis na época, pela cultura monástica.

O acervo remanescente de 97 manuscritos configurava-se maior, como comprova o registro daqueles títulos cedidos por empréstimos nos anos de 1207, 1218 e 1226. No registro de 1207 estão listados os livros cedidos a Pedro Vicente, cônego do mosteiro de São Vicente de Fora, de Lisboa, em que se encontram outros títulos de medicina, o Viaticus peregrinantis ou Kitab Zad al-musafir wa-qut al-hadir de Al-Aschaafar (ou Ibn al Jazzār) e o De gradibus simplicium, ambos traduzidos, com adaptações e reformulações do árabe para o latim, feitas pelo monge de Monte Cassino, Constantino, o africano, no séc. XI. O exemplar do Viaticus (ou Viaticum) provavelmente fazia parte do espólio de mestre Martim doado ao mosteiro. Consistia em um manual árabe de prática médica para viajantes que necessitassem de auxilio médico. A obra discutia diversas doenças e os respectivos remédios para a cura, seguindo o modelo tradicional de se iniciar pelas enfermidades da 
cabeça e finalizar com as dos pés. Devido a seu caráter prático, conheceu grande difusão ${ }^{2}$, atestada pelos manuscritos remanescentes. De gradibus simplicium é igualmente uma obra de practica medica, ou seja, um antidotário. Outro título encontrado nesse rol é Passionarius, de Garioponto (séc. XI), da Escola de Salerno, uma compilação de textos de vários autores médicos gregos e bizantinos, para uso didático. No segundo registro de empréstimo, de 1218, para Mestre Gil (Gil de Santarém?), aparecem tratados médicos agrupados como Libri ad Fisicam pertinentes (NASCIMENTO \& MEIRINHOS, 1997, p. 9; CRUZ, 1991, p. 192-193). No terceiro registro de empréstimo, para Pedro Peres (mestre crúzio?), em 1226, há uma obra não identificada do físico Petrus Munsadinus, de Salerno, e o manual de medicina Almansor, do filósofo e físico muçulmano Rhazis (865-925). Percebem-se nesse acervo crúzio obras de prática médica com grande utilidade para o exercício da medicina monástica, seja na domus infirmarum seja nos hospitia. Provavelmente esses livros eram guardados no armarium librorium junto do armarium pigmentrum, ou protobotica, onde se guardavam os materiais diversos usados na fabricação dos remédios ou mezinhas. A presença desses títulos médicos no acervo da livraria de mão crúzia constitui outro indício do interesse pelos estudos médicos no mosteiro coimbrão.

Desse modo, apesar da autonomia regional, havia uma abertura para o exterior, com a circulação de religiosos entre as casas da ordem no reino e além das fronteiras. Assim, para o mosteiro de Santa Cruz de Coimbra vinham regularmente religiosos da Espanha, da França e da Itália, que traziam consigo, entre outras, obras médicas. Para mais, alguns crúzios frequentaram outras casas e, mais tarde, cursos universitários na França, talvez em Montpellier ou Paris. Acerca desse costume, acham-se referências em dois documentos posteriores do século XVII, na Crônica do Mosteiro de Santa Cruz, de D. Timóteo dos Mártires (MADAHIL, 1960, pp. 103-122) e na Crônica da Ordem dos Cónegos Regrantes do patriarca S. Agostino, de Nicolau de Santa Maria (1668, p. 58). Tudo leva a crer que, na época de Sancho I (1154-1212), os crúzios iniciaram um ensino sobre ciências (medicina e farmácia) e enviaram alguns cônegos para estudar Medicina em Paris ou Montpellier, entre eles, D. Mendo Dias, sobrinho do prior Gonçalo Dias.

Além dos preceitos das regras há também outra documentação central para nossa pesquisa, os costumeiros (constitutiones) ou liber ordinis, datados desde o século VII. Sua principal finalidade era orientar diretamente o curso do tempo quotidiano dos ritos litúrgicos e dos usos e costumes dessas comunidades. No caso da medicina monástica, não apenas se definiam os tratamentos dos doentes, se determinavam as condições de funcionamento da domus infirmorum e os suprimentos necessários, como também se prescreviam hábitos de higiene pessoal. Para um 
exemplo do exercício dessa medicina em Portugal compulsamos o costumeiro do mosteiro de Santa Maria de Pombeiro, um dos 24 mosteiros beneditinos na arquidiocese de Braga, fundado nos finais do século XI. Seus patronos e benfeitores foram, primeiro, os membros infanções da linhagem dos Sousa e mais tarde, os Barbosa, que construíram a grande igreja abacial em estilo românico, com o propósito de ali serem sepultados (LENCART, 1997, p.49-50; VASCONCELOS, 2005, p. 68).

Enquanto outros costumeiros tradicionais se estruturavam a partir dos oficiais e da vida cotidiana dos monges, o de Pombeiro apresentava outra organização, com a influência do mosteiro de Sahagún, no reino de Leão. Percebe-se essa influência no santoral, que incluía dois santos lá cultuados, Facundo e Primitivo. Apesar das lacunas dos fólios, está dividido em dez partes e segue o tempo do ano litúrgico, intercalando-se entre os ofícios divinos (horas canônicas) alguns usos e costumes comunitários. Dentre esses costumes há menções reveladoras de algumas práticas médicas dessa medicina monástica.

\section{A domus infirmorum e as práticas da medicina monástica}

A enfermaria, ou domus infirmorum, constituiu o espaço do mosteiro beneditino ou crúzio destinado ao cuidado com os monges doentes, definido primeiro nas regras de fundação e depois presente em todos os costumeiros, ou liber ordinis, monásticos. O tamanho variava de acordo com o mosteiro, porém geralmente formava um edifício à parte, localizado a leste do claustro, seguindo prescrições hipocráticas, ligado por uma passagem coberta à construção central. No mosteiro crúzio, a enfermaria foi construída em meados do século XII. As rendas ou ovenças para o sustento da domus, da vestiaria, da sacristia e da adega dessas comunidades portuguesas provinham dos lotes dos domínios, cuja administração e arrecadação eram operadas pelos monges ovençais (obedentiales) (MATTOSO, 1985, p. 268).

Compunha ainda a organização da saúde dos monges o espaço do hortus (RSB, 66), o jardim onde o herbolarius cultivava ervas, condimentos e plantas medicinais. Esse local ao ar livre também servia para a recuperação dos enfermos em fase de convalescência ou neutralitas. $\mathrm{O}$ material colhido no hortus era utilizado na alimentação e na preparação dos remédios ou mezinhas, na forma de bebida, como elixir, ou de unguento, nas boticas primitivas. Nesse espaço de observação e de experimentação contínuas, a preparação seguia regras e procedimentos seculares, para depois ser administrada aos enfermos. Muitas vezes havia a associação de outras práticas mágico-religiosas nessas terapêuticas, que incluíam sinal da cruz, orações, beijar nas relíquias, sorver água benta, etc. Em Portugal, essas boticas monásticas foram referência até o final da Idade 
Média e para além dela, pois regulamentações sobre o ofício do farmacêutico e o controle dos preços dos produtos datam do final do século XV e o ensino farmacêutico se integrou ao ensino universitário no século seguinte (MARTINS, 2008, p. 18-19; PITA, 1997, p. 875).

No mosteiro de Pombeiro, os dois oficiais vinculados a domus infirmarium eram o enfermeiro (infirmarius), responsável pelo cuidado direto com os doentes, e o celeireiro (cellerarius) mor (RSB, cap. 31), auxiliado por seus ajudantes - o celeireiro minor, que o substituía em sua ausência e era encarregado de vigiar a cozinha, e os famuli cellerari, mais tarde chamados de ovençais. O segundo era uma personagem central que cuidava não apenas da dispensa como da distribuição dos víveres na comunidade e do regime alimentar dos enfermos. A importância do celeireiro advinha do conhecimento da teoria médica herdada do mundo antigo pelo galenismo árabe, que arrolava as seis coisas naturais e as seis não naturais necessárias para a preservação da saúde corporal. As primeiras compunham-se de noções da fisiologia do corpo humano importantes para seu funcionamento: os quatro elementos do universo, as compleições, os humores, as partes sólidas do corpo (cérebro, coração e fígado), as operações ou funções das partes sólidas (propagação da espécie, preservação da vida e a qualidade de vida) e as faculdades contributivas das maiores funções biológicas: formação, crescimento, locomoção e nutrição. As seis coisas não naturais englobavam os elementos externos à natureza do corpo humano, essenciais a seu funcionamento e à manutenção da saúde, entre as quais figuravam a alimentação e as bebidas, responsabilidade do celeireiro tanto para os monges sãos quanto para a recuperação dos enfermos. A alimentação equilibrada e o consumo moderado do vinho eram critérios da Dietética, um dos ramos da medicina, para uma vida salutar. Assim, a carne - cujo consumo era ausente em geral na dieta monacal, com a predominância do pescado e ovos - aparece como alimento fortificante na dieta dos enfermos e dos submetidos à sangria (minuti). As outras coisas não naturais incluíam: ar e meio ambiente; exercício e repouso, sono e vigilia, retenção e expulsão e as paixões da alma. $\mathrm{O}$ ar e meio ambiente eram levados em consideração no espaço da enfermaria e no cuidado com os jardins, onde os doentes respiravam ar puro, sem fumaça ou substância nociva, principalmente na primavera.

Além dos propósitos de prevenir ou minorar os sofrimentos e as misérias humanas, é preciso pensar as práticas da medicina monástica a partir de dois enfoques diferentes, mas complementares. Primeiro, elas estavam inseridas no contexto de uma concepção religiosa de saúde/doença em que não se fazia distinção entre corpo e alma. Portanto, não se distinguia também entre uma cura superior da alma e uma inferior do corpo, pois se buscava praticar uma única cura global do ser 
humano. Assim, aqueles monges médicos ou enfermeiros que se dedicavam aos tratamentos faziam, de certa maneira, a mediação entre esses dois planos, o da medicina corporal e o da salvação da alma, integrando-as de fato. Eles eram os mediadores porque quem detinha o verdadeiro poder da cura era Jesus Cristo, cuja maior parte dos milagres constituiu-se de cura de doenças. Essa vinculação da cura com o seu poder vem desde os textos da Patrística, em que Cristo era designado como o salvador e o iatrós (o médico) até o século XIII, quando foi denominado Supremo Médico, pelo físico português Pedro Hispano, e Médico Perfeito, nos sermões do dominicano Frei Paio de Coimbra. Desse modo, a restituição total da saúde física caminhava junto com a salvaguarda da espiritual. Nessa linha, no costumeiro de Pombeiro havia também a recomendação da missa para os enfermos (CP f. 86r; p. 351).

As práticas de prevenção e de cura, por sua vez, estavam embasadas nas teorias médicas herdadas da Antiguidade greco-romana, anteriores ao cristianismo, que foram autoridade durante toda a Idade Média e para além dela. A principal doutrina médica criada por Hipócrates e a escola de Cós na Grécia (V sec. a. C), depois reformulada por Galeno (II sec.) no Império Romano, foi a teoria humoral. Esta buscava explicar o funcionamento interno do corpo humano saudável a partir da noção de equilibrio dos quatro humores, ou líquidos corporais. $\mathrm{O}$ termo sangue era polissêmico, pois designava ora um dos humores, o líquido das veias, e ora o humor principal, que continha a mescla dos outros três - a fleuma, a bílis amarela e a bílis negra - interligados. Tratava-se de uma teoria em que os humores são elementos explicativos, substâncias sem comprovação empírica direta, eixos fundamentais para explicar a realidade biológica dos seres humanos. Assim, a enfermidade era resultado do desequilibrio dos líquidos corporais. Galeno introduziu o conceito de compleição (complexio), que se tornou o princípio organizador de cada corpo humano, considerado um todo. Assim, engloba a constituição física, a disposição do espírito e o temperamento dos indivíduos. A inter-relação dos quatro elementos constituintes do universo - terra, água, ar e fogo -, os humores e a mistura das qualidades - quente, frio, seco e úmido - compreendiam os temperamentos individuais, também classificados em quatro modalidades: sanguíneo, colérico, fleumático e melancólico.

Nessa linha de reflexão, ao mesmo tempo religiosa e médica, inseria-se a prática terapêutica e cirúrgica da sangria, minuere sanguinem ou flebotomia, nos mosteiros medievais. Herdada da medicina clássica do mundo antigo e concretizada pelo galenismo árabe, na Idade Média essa técnica foi regulada por procedimentos codificados numa literatura médica específica, composta de textos breves ou epístolas de flebotomia. Essa literatura tinha o objetivo de responder às questões 
práticas e teóricas postas aos médicos e cirurgiões-barbeiros no exercício do seu ofício. Desse modo, integrava a rotina de atividades de saúde dos mosteiros e estava presente em capítulos dos costumeiros, ou liber ordinis, de todas as ordens monásticas medievais. Consistia em incisão cirúrgica correta de certas veias pulsantes e consequente efusão do sangue, que continha em si a mescla dos quatro humores. A sangria era adotada com duas finalidades principais: a manutenção da saúde (enquanto profilaxia) e a curativa. Atuava pela eliminação ou evacuação dos resíduos da matéria patologicamente alterada a fim de corrigir os excessos do sangue, o humor principal, (phletora) ou a sua corrupção (cacoquimia), enfim, as alterações humorais que provocavam as enfermidades (SOTRES, 1986, p. 8). Era exercida por monges letrados ou não, mas com a expertise no manejo da navalha e da lanceta. Às vezes era o mesmo irmão que fazia o corte de cabelo da tonsura (tonsor), a barba (rasor) quinzenalmente ${ }^{3}$ (conforme as épocas do ano) e a sangria (minutor). Na ausência deste, eram chamados sangradores ou cirurgiões-barbeiros laicos. Nos costumeiros havia indicações variadas da frequência desse procedimento, sendo geralmente quatro, nos cluniacenses, e cinco, nos crúzios, as sessões de sangria profiláticas periódicas por ano. Os períodos da minutio generalis nas comunidades aconteciam nas calendas de setembro, no outono, na festa de São Martinho de Tours (11 de novembro), por ocasião do Natal, em dezembro, depois da páscoa, na primavera, e no mês de junho, em torno da festa de São João.

$\mathrm{Na}$ concepção religiosa de saúde do corpo imbricada com a da alma, quando o monge minutor fazia a incisão para retirar o sangue da veia visava à extração da matéria doentia, tão funesta para a saúde corporal da mesma forma que a confissão dos pecados constituía remédio para a saúde espiritual. Outra particularidade da medicina monástica masculina era o uso da sangria como medida profilática para a preservação da continência sexual por intermédio do restabelecimento do estado natural de equilibrio humoral. Pois, na medicina clássica e medieval, o sêmen masculino era uma substância originária do sangue e elaborada nos testículos, e sua retenção - consequência tanto da abstinência sexual monástica quanto do pecado da gula - era considerada prejudicial à saúde corporal dos homens. Isso porque a retenção tornaria o indivíduo irritável, preguiçoso, depressivo e propenso ao pecado capital da acídia, com sua manifestação física, a plethora ou plenitudo, ou seja, o aumento quantitativo e proporcional dos humores no corpo (SOTRES, 1986, p. 9).

O procedimento da sangria era seguido de três dias de descanso (recreativo ou licentia minuendi), com dispensa da participação dos ritos litúrgicos (CP f. b $5 \mathrm{v}$ p. 330), e de uma alimentação especial fortificadora (pietancias e mixtum) em que se incluía a carne, como revela o 
costumeiro do mosteiro de Pombeiro (CP f. 1r, p. 321-322). Essa recreatio era pensada como período de descanso, com dupla finalidade - recuperação da saúde do corpo por intermédio da alimentação e fortalecimento e renovação do espírito por meio da palavra de Deus. Um corpo saudável facilitava a atenção do monge para as questões espirituais e transcendentes (YEARL, 2011, p. 219). Além dos minuti, conforme o estado do monge enfermo também se adotavam critérios de excepcionalidade, como o abrandamento na participação das atividades quotidianas, como no caso da tripla dispensa da leitura em alguns períodos do calendário litúrgico, Quaresma, vigilia de Natal e dos santos, 6as Feiras, etc. ${ }^{4}$, da frequência ao coro e do jejum e da abstinência de carne. No costumeiro de Pombeiro há ainda prescrições minuciosas de diversas práticas de higiene corporal, tais como lavar as mãos, o rosto e os pés, pentear os cabelos, trocar calçados diurnos e noturnos, etc (CP ff 10v, 33r, 34v, pp. 248, 334).

Oriunda do mundo antigo, outra prática terapêutica adotada para os enfermos era a terapia dos banhos termais, em virtude de as águas minerais serem consideradas remédio de origem divina. Em Portugal, algumas nascentes de águas de composição variada foram utilizadas desde os tempos da ocupação romana, tais como Lafões, Vizela, Caldas da Rainha, que no século XII receberam proteção régia e de alguns senhores, os quais construíram tanques e balneários para uso dos enfermos. Essa terapia de tradição popular foi depois incorporada pelos físicos escolásticos, que passaram a indicá-la para certas enfermidades crônicas ou não, a saber, doenças da pele, como a sarna e a lepra, os cálculos renais, a artrite, dores corporais e até problemas oftálmicos, entre outros. No galenismo árabe, o banho aparece como complemento do exercício físico (terceira coisa não natural) ou como expulsão (quinta coisa não natural), creditando-se sua ação principal à eliminação das substâncias supérfluas. Há referências explícitas à terapia dos banhos para os enfermos de compleição frágil, nas duas regras - a beneditina e a agostiniana -, embora com seu interdito ao uso pelos irmãos saudáveis, sobretudo os jovens, e com indicação do abade ou prepósito.

O uso dos banhos seja oferecido aos doentes sempre que convém; mas aos sãos, e sobretudo aos jovens, seja raramente concedido. (RSB, cap. 36)

O banho, inclusive do corpo, de forma nenhuma seja negado quando o exigir a necessidade de uma compleição frágil. E faça-se sem murmuração quando a medicina aconselha de tal modo que, mesmo quando alguém não queira, a uma ordem do Prepósito faça o que deve ser feito para a saúde. Se, porém, quiser, e não for conveniente, não se obedeça a seu desejo. Às vezes crê-se proveitoso aquilo que agrada quando, na verdade, é nocivo (RSA, cap. V). 
Até o final do século XII, observa-se a inexistência de um ensino formal estruturado dessa área denominada oitava arte do trivium e do quadrivium, em Portugal. Essa constatação não descarta o fato de que houvesse o interesse e a transmissão dos conhecimentos médicos nos mosteiros. Uma das razões encontra-se nas regras monásticas na delimitação dos espaços internos favoráveis a esse desenvolvimento. Portanto, essas casas monásticas beneditinas e crúzias constituíram-se nos principais centros documentados de bibliotecas com acervo de obras médicas e de estudos e do exercício regular da medicina na Europa, dentro e fora de seus muros.

\section{A inflexão da medicina monástica nos séculos XII e XIII}

A partir do século XII, ocorreu a redescoberta de um corpus de obras de filosofia natural de Aristóteles e as do galenismo árabe, traduzidas para o latim por religiosos em Toledo, na Espanha, e em outros centros. Esses textos revolucionaram o conhecimento médico, pois buscavam explicar racionalmente o mundo da natureza e seus fenômenos saúde e enfermidade. Esses textos foram estudados na Escola de Salerno e depois na escolástica médica das principais faculdades de medicina de Paris, Montpellier e Siena. Outro momento de inflexão da medicina monástica ocorreu paralelamente ao surgimento e desenvolvimento dos Studia Generalia, lócus do ensino institucionalizado universitário. O primeiro movimento na direção da institucionalização do ensino de medicina foi com a Escola de Medicina de Salerno (sécs. XI-XII), em que os autores salernitanos organizaram uma coleção de pequenos tratados de médicos gregos, latinos e árabes medievais, denominada Articella. Esta coletânea tornou-se posteriormente à base da escolástica médica com a criação das Faculdades de Medicina nos Estudos Gerais, sob a autoridade pontifícia ou régia, de Bolonha, Paris e Monpellier, entre outras. Em Portugal, a Universidade foi criada pelo poder régio, no reinado de D. Dinis, em 1290, e depois aprovada pela bula do papa Nicolau IV, De statu regni Portugaliae, no mesmo ano. As suas faculdades ofereciam os cursos de Artes, Cânones (Direito Canônico), Leis (Direito Civil) e Medicina, inicialmente com apenas uma cátedra. Não foi instituído o curso de Teologia, deixado a cargo das ordens monásticas. Todavia, é preciso ressaltar a hierarquia estabelecida no período entre as áreas do conhecimento: primeiro a Teologia, em seguida o Direito civil e canônico e, por último, a Medicina, a qual repercutia inclusive nas diversas remunerações recebidas pelos mestres (COSMACINI, 2009, p. 129).

Abriu-se o caminho para a medicina deixar de ser apenas uma arte mecânica do fazer, uma techné ou ars, uma atividade prática fundamentada na experiência, que buscava (e ainda busca) aliviar o sofrimento de homens e mulheres advindo dos males e das doenças. Por outro lado, a 
medicina podia ser entendida como uma sciencia ou epistemé, já que implicava racionalidade, explicação causal, observação, indução e dedução, previsões e hipóteses. Nesse sentido, o desenvolvimento de um pensamento especulativo (ratio) e do método dialético-disputador da escolástica médica, voltada para a discussão dos textos das autoridades antigas e medievais nos campos da filosofia natural aristotélica e da medicina galênica pela via dos árabes, legitimou seu estatuto de ciência teórica (COSMACINI, 2010, p. 266; JACQUART, 1995, pp. 175-210).

Uma vez que os religiosos regulares adquiriram uma expertise no exercício da medicina em suas comunidades, sua fama extrapolava os muros destas. Assim, seus serviços foram demandados e eles passaram muitas vezes a atuar fora, com ou sem remuneração. Com o advento das universidades, o passo seguinte foi o deslocamento para a continuação dos estudos médicos. Assim, no século XIII os frades mendicantes, em especial os franciscanos e dominicanos, frequentaram os cursos de medicina nos studia generalia.

Em Portugal, Gil Rodrigues de Valladares - denominado frei dominicano Gil de Vouzela, depois conhecido no exterior por Frei Gil de Santarém (c. 1890-1265) - iniciou seus estudos de língua latina, filosofia e medicina no mosteiro crúzio e depois foi enviado por Sancho I a Paris para aperfeiçoar-se, já que seu pai, D. Soeiro Paes de Valadares, era de linhagem nobre e exerceu o cargo de mordomo-mor da corte. No Vitae fratum ordinis praedicatorum há o registro dos serviços médicos prestados por ele na enfermaria do convento da ordem dos pregadores de São Tiago, em Paris. Escreveu textos de receitas médicas e traduziu do árabe para o latim o Liber de secretis medecinae de Rhazes. A partir de suas habilidades médicas e de outras alegadas competências, como a de nigromante, construiu-se um conjunto de lendas acerca de um pacto diabólico. Apesar disso, Frei Gil constituiu exemplo concreto da continuidade desse interesse monástico pela medicina em Portugal (MONTFORD, 2004, p.111; MCLEERY, 2005, p. 120). Outro exemplo mais tardio, do século XIV: o mestre João Vicente, fundador da Congregação dos cônegos seculares de São João Evangelista, conhecida como ordem dos loios, tinha formação médica. Assim, além de religioso, atuou como professor na Universidade de Lisboa. No século seguinte, aos poucos os loios assumiram a administração do Hospital de Todos os Santos e de outros hospitais, como os de Santarém, de Montemor-o-Novo, de Caldas da Rainha, de Coimbra, etc. Encarregaram-se da assistência aos doentes e moribundos nos surtos de pestes de 1458, 1493, 1569 e 1579 (VASCONCELOS, 2005, p. 235-236).

Outro físico português, Pedro Hispano (c. 1220-1277), sem entrar nas controvérsias entre historiadores e filósofos sobre a autoria das obras filosóficas e médicas que lhe são atribuídas, 
destacou-se também como médico fora de Portugal. Iniciou seus estudos básicos em Lisboa, provavelmente na escola catedralícia ou em algum mosteiro. Depois, dirigiu-se para a França, talvez na comitiva do então príncipe Afonso, futuro rei Afonso III, para a corte do tio, Luís IX. Em Paris, estudou medicina, seguindo o costume peninsular. Há documentação comprobatória de sua atuação como mestre, na Faculdade de Medicina em Siena, entre 1245 e 1250. Além disso, temos um conjunto de comentários médicos à Articella, com muitos manuscritos remanescentes em várias bibliotecas europeias. A partir de 1260, desenvolveu sua carreira eclesiástica no clero secular, sendo então encontrado na cúria pontifícia de Viterbo, onde atuou como físico dos cardeais e papas desde a época de Urbano IV (1261-1264), depois Gregório X (Tedaldo Visconti, 1 set. 1271-10 jan. 1276), Inocêncio V (Pierre de Tarentaise, 21 jan.-22 jun. 1276) e Adriano V (Ottobono Fieschi, 11 jul.-18 ago. 1276). No século XIII, a ciência médica deteve grande prestígio na corte pontifícia de Viterbo, um dos grandes centros culturais do Ocidente latino, onde viviam físicos, juristas, matemáticos e astrônomos - $40 \%$ dos familiares dos papas do período tinham o título de magister. Pedro Hispano tornou-se cardeal de Túsculo (Itália) em 1273, integrando o Colégio dos Cardeais, e dois anos depois ascendeu ao trono pontifício com coroação na catedral de São Lourenço de Viterbo, com o nome de João XXI. Seu pontificado foi breve (setembro de 1276 a maio de 1277), em virtude de sua morte no desabamento de uma das alas em construção do palácio de Viterbo. Deixou um conjunto de obras médicas, que lhe são atribuídas, mas se faz necessária uma investigação mais acurada dos inúmeros manuscritos remanescentes nas bibliotecas europeias a fim de que se levantem mais dados para esclarecer concretamente as polêmicas autorais entre os estudiosos. Além dos comentários, produziu tratados e obras de prática médica, compulsadas até o século XVIII.

Ao longo do século XII, os religiosos da alta hierarquia da Igreja católica mostraram uma política voltada para a delimitação de seu espaço/ fronteira em oposição ao do mundo laico. Nesse sentido, a Igreja adotou medidas de controle da atuação dos monges e frades médicos. Essa inquietação deu origem a toda uma legislação conciliar que restringia o estudo e a atuação dos monges médicos além de se preocupar com a má gestão das esmolas para os pobres e enfermos. Está expressa inicialmente nos cânones de diversos sínodos regionais como, por exemplo, o cânone 9 do II Concílio de Latrão (1139): "prometem saúde em troca do dinheiro detestável”, reforçando a condenação do ofício do trabalho do monge médico remunerado e condenando os abades que consentissem essas irregularidades. O sínodo de Paris (1212 ou1213) teve como principal objetivo melhorar a situação eclesiástica na França, e em duas partes dele encontram-se passagens relativas à 
medicina monástica. Na segunda parte, relativa ao aperfeiçoamento da vida monástica, dois itens merecem destaque. O primeiro é o item 4, que propõe: "Os monges devem se ocupar dos doentes e das pessoas fracas, e não fazer mal emprego das esmolas recebidas para esse fim e para construir as enfermarias", revelando-se a má gestão desses recursos. O segundo aborda outro aspecto, o das atividades extramuros dos mosteiros dos monges médicos: "Nenhum monge deve, sob o pretexto de dar consultas de direito ou medicina, habitar fora do convento, mesmo com a permissão do abade: pois este não pode permiti-lo" (4 e 20; HEFELÉ, 1872, p. 106,107-108). Outros decretos conciliares referem-se às restrições do tratamento e do contato com o corpo das mulheres, inclusive o exame de urina, principal detector dos indícios das perturbações internas.

Os 70 cânones do IV Concílio de Latrão (1215), dirigido pelo papa Inocêncio III (1198$1216)^{5}$, foram um divisor de águas quanto a autorreforma eclesiástica, questões doutrinais, prática sacramental e, inclusive, a imposição da prática de confissão auricular, aspectos já muito analisados pela historiografia sobre a Igreja medieval. Assim, a maior parte desses capítulos foi depois incorporada aos cânones do Corpus Iuris Canonici, do Direito Canônico. Além disso, marcou posição nos capítulos XVIII $^{6}$ e XXII $^{7}$ e colocou em prática a reforma que proibia aos membros do clero secular e regular praticarem algumas atividades médicas cirúrgicas, sobretudo aquelas que envolvessem o contato com o sangue corporal, queimar com cautério (metal quente) ou fazer incisões. Essas atividades eram normalmente desempenhadas por barbeiros (sangradores) ou cirurgiões-barbeiros laicos, a quem a Igreja delegava essas funções. Dessa maneira, a prática da cirurgia em pacientes com ferimentos e chagas estava entre estas ações que o Papa identificava como impróprias e dissonantes da vocação clerical. Outro lado da questão era o fato de os monges exercerem a medicina e tal prática resultar em fonte de lucros materiais e habitar extramuros do mosteiro, pois isso era considerado desvio tanto do cuidado médico como caridade quanto do voto de pobreza santa. Podiam continuar a prática caritativa da cura sem auferir ganhos por isso (HEFELÉ, 1872, pp. 132 e134). Por outro lado, em virtude do conhecimento e da experiência acumulados, eles eram demandados para tratamentos que visavam à cura dos doentes seculares, sendo que, inclusive, alguns se tornaram médicos da corte régia, às vezes lado a lado com físicos judeus e outros, na cúria pontifícia.

Outro aspecto da medicina monástica aparece na Bula Super specula (1219) do papa Honório III (1148-1227), que proibia certas categorias de religiosos de deixar suas casas por mais de dois meses para estudar temas seculares, tais como direito civil e medicina. Essa proibição coincidiu com as restrições ao estudo dos textos de filosofia natural de Aristóteles (libri naturales) 
nos Studia Generalia, sobretudo em Paris. A justificativa principal apresentada era o fato de que a atração pela carreira médica de monges e cônegos poderia atrapalhar suas intenções de estudar Teologia. Na realidade, alguns mostravam interesse por ambas as áreas, Teologia e Medicina.

Mas, não se pode esquecer a diferença que existe entre a norma e o vivido. Dessa maneira, a persistência dessas proibições em muitos sínodos, concilios e bulas pontifícias demonstra a continuidade e a recorrência do exercício da medicina pelos monges, sobretudo, os cluniacenses.

Em suma, todos os indícios analisados apontam para uma Medicina monástica eficiente e atuante no reino de Portugal, nos séculos XII e XIII, conforme os padrões teóricos e práticos do período. A investigação em textos normativos religiosos, regras e costumeiros de dois mosteiros portugueses - Santa Cruz de Coimbra e o de Pombeiro - foi profícua. Revelou as disposições ideais de funcionamento das comunidades religiosas masculinas, fosse a agostiniana ou a beneditina cluniacense. Nesses textos normativos encontra-se a busca pelo controle e ordenamento total do tempo litúrgico quotidiano, e a preocupação com as correções evidencia a ocorrência constante de transgressões às normas e a necessidade das reformas das regras, de tempos em tempos. No entanto, no caso da medicina monástica as regras lançaram diretrizes com base nas virtudes caritativas, que favoreceram a criação de espaços próprios para a hospitalidade, a enfermaria e o hospital/albergaria, o cuidado dos doentes e as diversas práticas salutares e terapêuticas. Além disso, favoreceram igualmente o desenvolvimento das habilidades médicas de alguns monges que passaram a exercer a medicina fora do espaço monástico e de outros que se projetaram com destaque no exterior, como o frei Gil de Santarém e o secular Pedro Hispano, que se tornou papa João XXI.

Por outro lado, algumas casas extrapolaram esse ideal caritativo do cuidado aos pobres, doentes, e irmãos enfermos para se tornarem centros de estudos médicos, como ocorreu com a experiência do mosteiro de Santa Cruz de Coimbra. A presença de obras médicas em sua livraria de mão e sua circulação por meio dos empréstimos a mestres de outras comunidades atestam o interesse dos crúzios, entre outros, pelos estudos médicos. Nota-se igualmente na escrita religiosa dos sermões a adoção de metáforas médicas, intercambiando as noções de saúde do corpo e de saúde espiritual ou da alma, ou considerando Jesus Cristo o Supremo Médico ou o Médico perfeito.

Ao lado do discurso religioso hegemônico nos mosteiros, percebe-se também a influência das teorias médicas do galenismo árabe nas práticas de saúde dos monges, herdeiros e conservadores do patrimônio de textos da medicina clássica da Antiguidade, pela via árabe. Nesse contexto, a presença de uma cultura médica possibilitou o desenvolvimento da medicina monástica, com suas práticas profiláticas e terapêuticas. Algumas dessas práticas de saúde - tais como ambientes 
arejados, alimentação equilibrada, consumo moderado do vinho - mostram semelhança com o discurso da medicina preventiva da atualidade. Outras, por sua vez, causam estranheza a nosso olhar de século XXI, porque foram abandonadas há algum tempo. A sangria constitui um desses exemplos de práticas intrigantes, mas que tinha razão de ser, em razão de estar afinada com a teoria médica humoral e das compleições corporais do galenismo árabe da época, a qual fazia do sangue o principal líquido corporal e o centro da vida. Essa e outras teorias foram ultrapassadas por novas descobertas; além disso, ocorreu o desenvolvimento do conhecimento da anatomia humana, a partir da superação do tabu do corpo morto e pelo aperfeiçoamento, nos cursos de medicina, das técnicas de dissecação.

$\mathrm{Na}$ extensa legislação conciliar da Igreja católica, do século XIII, encontra-se a condenação contínua do exercício da medicina feito pelos monges, sobretudo daquelas práticas que envolvessem contato com sangue corporal. Tentou-se igualmente coibir o contato dos frades médicos com mulheres doentes e o respectivo exame de urina e o trabalho remunerado, com atendimento a doentes fora de suas comunidades. Além disso, buscou-se proibir a frequência de monges e frades em cursos de medicina e direito, admoestando-se o abade que o permitisse. A persistência dessas restrições revela as constantes transgressões e, também, quão grande era - e ainda é - o fosso entre a norma e o vivido.

\section{Referências Bibliográficas}

A REGRA DE SÃO BENTO. 2a . Ed. ver.Trad. de D. João Evangelista, O.S.B. Rio de Janeiro: Ed. Lumen Christi, 1980. p.45

COSMACINI, Giorgio. L'arte lunga. Storia della medicina dall'Antichità a Oggi. 6ed. Roma-Bari: Laterza, 2009.

La medicina medievale e il suo statuto filosófico. In: FUMAGALLI, Mariateresa et al. Luoghi e voci del pensiero medievale. Milano : Encyclomedia, 2010. p.264-269.

CRUZ, António. Santa Cruz de Coimbra na cultura portuguesa da Idade Média. Porto: 1963-1964. p. 191-209.

HEFELÉ, C. J. Histoire des conciles d'après des documents originaux. Paris: Adrien Le Clere, 1872.

JACQUART, Danielle. La scolastique médicale. In: GRMEK, Mirko D. et al.(org.). Histoire de la pensée médicale en Occident. Paris: Le Seuil, 1995. p. 175-210. v. 1. 
LENCART, Joana. O mosteiro de Pombeiro. In: O costumeiro de Pombeiro. Uma comunidade beneditina no século XIII. Lisboa: Estampa, 1997. pp. 23-169.

MADAHIL, Antonio Gomes da (ed.). A Cronica do Mosteiro de S. Cruz de Coimbra de D. Timóteo dos Mártires. O Instituto, 1960, pp. 103-122.

MARTINS, Ana Maria Tavares. O mosteiro como espaço de recuperação do corpo e do espírito. In:

MARQUES, Maria Alegria F. (org.) Mosteiro e saúde. Cerca, botica e enfermaria. São Cristovão de Lafões: Sociedade do Mosteiro de São Cristovão de Lafões, 2008. p. 13-24.

MARTINS, Armando A. O mosteiro de Santa Cruz de Coimbra na Idade Média. Lisboa: Centro de História/ Universidade de Lisboa, 2003.

MATTOSO, José. Panorâmica da História beneditina portuguesa durante a Idade Média. In: Portugal medieval. Novas interpretações. Lisboa: Imprensa Nacional/Casa da Moeda, 1985. pp. 259-272.

MCLEERY, Iona. Saintly Physician, Diabolical Doctor, Medieval Saint: Exploring the Reputation of Gil de Santarém in Medieval and Renaissance Portugal. Portuguese Studies, 21, 2005. pp. 112135.

MEIRINHOS, J. F. Ecos da renovação filosófica no século XII em Portugal: a cultura que vem da Europa e o legado árabe. In: Actas do 2º . Congresso Histórico de Guimarães, 1996, pp.153-170. Disponível em: <<repositorio-aberto.up.pt/.../2/josemarquesdoacoes000095915.pdf.>> Acesso em 06/10/2011.

MONTFORD, Angela. Health, sickness, medicine and the friars in the thirteenth and fourteenth centuries. Aldeshot (UK): Ashgate, 2004.

NASCIMENTO, Aires A., MEIRINHOS, José Francisco et al. (coords.) Catálogo dos códices da livraria de mão do mosteiro Santa Cruz de Coimbra na Biblioteca Pública Municipal do Porto. Porto: BPMP, 1997.

O COSTUMEIRO DE POMBEIRO. Ed. de Joana Lencart. In: O costumeiro de Pombeiro. Uma comunidade beneditina no século XIII. Lisboa: Estampa, 1997. p. 179-397.

PITA, João Rui. Farmácia. In: História da universidade em Portugal. Coimbra: Universidade de Coimbra/ Fundação Calouste Gulbenkian, 1997. p.875-881.

SANTA MARIA, Nicholas de. Chrónica da Ordem dos Cónegos Regrantes do patriarca S. Agostino. Lisboa, 1668.

SOTRES, Pedro Gil. Scripta minora de Flebotomia en la tradición medica del siglo XIII. Santander: Universidad de Cantábria; Pamplona: EUNSA, 1986.

SOUZA, Bernardo Vasconcelos. Ordens religiosas em Portugal. Das origens a Trento- Guia histórico. Lisboa: Horizonte, 2005. 
YEARL, Mary K. K. Bloodletting as recreation in the monasteries of medieval Europe. In: GLAZE, Florence Eliza \& NANCE, Brian K. (eds.) Between text and patient. Firenze: Sismel/Galluzzo, 2011. pp. 217-243.

Principais abreviaturas:

CP -Costumeiro de Pombeiro; CCSCC - Catálogo dos códices da livraria de mão do Mosteiro de Santa Cruz de Coimbra; RSA - Regra de Santo Agostinho; RSB - Regra de São Bento.

\section{Notas}

${ }^{1}$ Cassiodoro indicava a presença de monge com conhecimentos médicos em sua comunidade.

${ }^{2} \mathrm{Na}$ livraria do rei D. Duarte existia um exemplar do Viático, traduzido do latim para o português arcaico.

${ }^{3}$ A Pascha usque in festivitate Sancte Luce,a quindecim in quindecim debus vos debemus radere" CP, f. 100 r, p. 376.

${ }^{4} \mathrm{Si}$ vero infirmi fuerint ut a lectulis surgere non possint non eis imponimus legem nisi in diebus Quadragesime et in Quatuor Temporibus anni et in vigilia Natali Domini et vigilia sanctorum et sexte ferie. (CP f. 6v, p. 181)

${ }^{5}$ Este papa foi o primeiro a construir a casa dos médicos (domus medici) na cúria pontifícia e a propiciar a cópia de textos da área, além da fundação da Albergaria de Santa Maria in Sassio (1198-1201), depois Santo Espírito em Sassia, em Roma, sob a administração da ordem masculina francesa, da região do Languedoc, denominada de hospitalários do Santo Espírito (1170).

${ }^{6}$ Corpus Iuris Canonici, c. 9 , X.

${ }^{7}$ Corpus Iuris Canonici, c. 13, X.

Recebido em maio de 2012. Aprovado em junho de 2012. 